\title{
Introduction-Opening educational systems to cultural diversity: International and comparative perspectives
}

\author{
Abdeljalil Akkari • Colleen Loomis
}

Published online: 30 June 2012

(C) UNESCO IBE 2012

Keywords Cultural diversity · Education systems · Education reform · Language · Curriculum · Teachers

Contemporary educational systems that welcome all young children regardless of gender, ethnicity, religion, etc. first emerged in Europe during the 19th century and then became shared by most contemporary societies. Despite some initial ambivalence, schooling is becoming globalized (Akkari and Payet 2010). On the one hand, these changes reflect at least a partial realization of a centuries-old dream of education as the formation of rational and equal citizens. On the other hand, schools have been conceptualized from the perspective of a national identity based on one culture and language. The school has never been a culturally neutral place. The work of teachers in the classroom is organized around a cultural basis for instruction and learning, in which they explicitly and implicitly transmit a large amount of cultural information. In situations where teachers and students share a common culture and language, few cultural barriers to education exist. When teachers and students come from different backgrounds, however, the school curriculum and teaching practices may exclude some students and fail to support them in their learning. Racism and issues of power are omnipresent. Educational systems are inextricably linked with the development and lived experiences of students' cultural identities.

Given this background, we see the need for further critical reflections on the status of cultural diversity in education systems. While this thinking is hardly new (Banks et al. 1986; Berque 1985), it has been confined mostly within national spaces. This special issue broadens our thinking on cultural diversity within educational systems to an international and comparative perspective using illustrations of educational innovations circulating

\footnotetext{
A. Akkari $(\bowtie)$

Faculté de Psychologie et des Sciences de l'Éducation, Université de Genève,

Boulevard du Pont-d'Arve, 1211 Geneva, Switzerland

e-mail: Abdeljalil.Akkari@unige.ch

C. Loomis

Department of Psychology, Wilfrid Laurier University, 75 University Ave West,

Waterloo, ON, Canada

e-mail: cloomis@wlu.ca
} 
around the world, which may serve as models or templates for enhancing schools' capacity to embrace all young children.

In this introduction to the special issue we begin by juxtaposing the potential that schooling can oppress with its potential to liberate. Next, to better understand these opposing processes, we describe the role of comparative research and then highlight three dimensions of educational systems that show us both the difficulties and the interest in opening educational systems to cultural diversity: language, curriculum, and teachers. Finally, we discuss in more detail a fourth dimension: the dominant educational policy, i.e., the teaching methods preferred in schools. We refer to the extant literature and highlight new offerings in this special issue.

We begin our exploration of how educational systems are opening to cultural diversity by examining two facets of the schooling process. On the one hand, as Bourdieu and Passeron (1977 [1970]) put it so well, the modern school is an instrument of domination that perpetuates and reproduces hidden social inequalities. Individual students' relationships to knowledge and education can be used to sort them according to their socio-cultural proximity to the school culture. This proximity is reflected in the ways they learn, speak, behave, and act. On the other hand, the school contributes to the awareness and empowerment of oppressed groups. Analyses of decolonization movements clearly show that access to schooling is a crucial first point in the process of liberation. If any opening to cultural diversity has occurred in recent decades, it has been part of a long and difficult process dating back to before visible signs were evident, and it is still incomplete. Despite the difficulties and the long road still to be travelled before schools open seriously to cultural diversity, the texts presented in this issue reveal another horizon of possibilities. Issues of inequality and social injustice are still found all over the world. Indeed, schools often fail to reduce the discrimination suffered by certain groups as evidenced by some countries that still do not consider affirmative action policies in education in order to address inequality. While some of the debates on these topics seem to be universal, the answers are always local and national-hence, the importance of comparative and international research.

Some recent comparative studies are providing evidence that will help us to better understand the role that culture plays in education. By combining detailed analyses across the local, national, and international levels, these studies strengthen the legitimacy of the comparative perspective. The relationship between discourse and the national integration models and logics at work within schools and classrooms has also attracted the attention of researchers. One such study contained in this issue is Diane Gérin-Lajoie's article on Canadian schools in monolingual English school boards. Recently, researchers have capitalized on national experiences to identify the factors that favour the recognition and enhancement of cultural diversity in education systems, and have specifically recognized the cultural diversity of indigenous peoples. It seems obvious that more comparative research on this problem is useful because it allows us to contrast the results of research on this topic and because we can use our methodologies to compare and identify innovative practices that may be transferred from one context to another or even internationally. Moreover, researchers in the South, especially Latin America and Asia, have produced original studies that deserve to be shared by researchers based in Europe or North America. These studies highlight four critical dimensions of educational systems: language, curriculum, teachers, and educational policies and practices.

Consider first the language of instruction at school. With few exceptions, education systems are still governed by monolingual practices. Observers point out that the choice of languages used in schooling is not only relevant to the child's mother tongue but also that 
bilingualism has cognitive benefits (Akkari and Loomis 1998). Using a child's first language (the one spoken at home with parents and community) in instruction during the early years of education has cognitive benefits (Cummins 1979). Conversely, when the home language is different from the language of instruction, specific pedagogical and cognitive problems result (Klein 1994). The important role that language plays in welcoming students is illustrated in this issue by the cases of monolingual schools in Canada (GérinLajoie) and students in an international school in Brazil (Nigel Bagnall). Still, evidence points to the need for caution around educational reforms that address only language issues because it is possible to perpetuate or recreate educational systems that remain closed to cultural diversity. As Suseela Malakolunthu and Nagappan Rengasamy describe in this issue, this was the case in Malaysia, where changes were made to use the indigenous language but other aspects of education retained the colonial practices. These authors report on the rich and complex history of the interplay among the Malay, Mandarin, and Tamil languages as well as English and other foreign languages taught as second languages in schools. A consistent theme is that, if educational systems are to be opened to cultural diversity, issues around language, curriculum, teachers, and educational policies must be addressed simultaneously.

Second, consider current approaches to the curriculum. That is, what is regarded as legitimate knowledge to be transmitted to future generations? If negative and stereotypical representations of certain cultures are now less common in textbooks, we are still far from seeing equitable representation of all cultures in the classroom. Serpell and Ganapathy (2002) showed that when teachers in training were offered a multicultural class with a multicultural curriculum, they could confront their own ethnocentrism and develop intellectual diversity among their experiences. This approach can allow minority teachers to address issues they rarely have the opportunity to discuss during their training such as racism, discrimination, and cultural duality. In this issue, Halima Ait-Mehdi shows us, through student accounts, that a critical area to address in French schools is the teaching of the history of colonization and decolonization, which remains Franco-centric. Changes to the curriculum are needed to make the content relevant to students' experiences of migration and the pluralistic society of France. And Malakolunthu and Rengasamy show how the Malaysian curriculum at different times in history has either reinforced racial differences or fostered racial unity at the school level through, for example, the Vision School or the Student Integration Plan for Unity. Also, the article in this issue by Abdeljalil Akkari on radical educational reforms in Brazil provides concrete examples of curriculum content changes that integrate antiracist and inclusive education with citizenship education. Bagnall also shows that within international schools with students from several cultures, some students develop a global identity and others do not, suggesting that there is room for curriculum changes that can teach these students how their lives are interconnected with others' lives.

Third, teachers are one pillar of the educational system and play a central role in promoting cultural diversity. As Akkari describes, members of cultural minority groups are underrepresented on teaching staffs. Moreover, the intercultural dimension of their initial and ongoing training remains small (e.g., Akkari, Loomis, and Bauer 2012). The first challenge today in teacher education and training is to create learning environments that maintain the cultural integrity of every child while increasing their academic achievement (Wlodkowski and Ginsberg 1995). As Gérin-Lajoie points out, teachers need more education and preparation to work with students who are not being instructed in their first language; this preparation needs to be expanded to include all teachers who will teach students in a second language. Further, because teachers are close to students, they are 
strategically positioned to provide experiences that allow all children to maintain their cultural integrity and gain an appropriate education. Drawing on international research, Akkari shows us how teachers can change their work by acting as catalysts in opening educational systems to cultural diversity that will drive the needed reforms in teacher education and training.

Finally, we move to a fourth issue, discussing it in slightly more detail: the dominant educational policies and practices that influence how school systems can be opened to cultural diversity. Here we focus on the teaching methods that both systems and teachers prefer. We have chosen to elaborate this point because all observers of contemporary educational systems agree that the treatment of cultural diversity is a challenge for educational policies. Many international organizations, including UNESCO and the Council of Europe, focus their programmes, projects, and actions on this issue. These organizations also contribute to disseminating intercultural approaches in education worldwide.

Among the educational practices that can embody either monoculturalism or cultural diversity are instructional and classroom management strategies, including teachers' assessments of students. We note, for example, that individuals from privileged, powerful, and dominant groups comprise most of the teaching corps around the world, but they are in fact a numerical minority of the world's population. Thus teachers belong to the "minority world" (Dasen and Akkari 2008). In the minority world, written communication is valued as more legitimate than oral communication, and measurable skills (valued in economic terms, such as mathematical knowledge) take precedence over social skills (solidarity, citizenship). The distance between educational practices and students' cultures is inversely related to students' academic achievement; as the cultural distance increases, students are less likely to achieve academically. This observation sets up a dilemma of us- versus-them and raises questions about how to promote cultural diversity in educational policies so that all children can succeed in school.

Research findings suggest that students from culturally diverse groups achieve more in school if schools and teachers ensure that both instruction and classroom management are sensitive to the students' cultural backgrounds. Scholars working within the realm of Anglo-Saxon educational research have coined several terms that reflect this strategy: the cultural (dis) continuity theory (Jacob and Jordan 1987), culturally appropriate education (Au and Kawakami 1994), culturally sensitive teaching (Novick 1996; Phuntsog 1999), and culturally relevant teaching (Ladson-Billings 1990). At the classroom level, culturally sensitive education essentially means that teachers use their students' cultural experiences to help them learn. But that is not enough. Educators must also increase learners' sense of school knowledge: the standards, procedures, and structures that enhance and refine the complexity of what they learn. This also includes the school's values and goals, which help students to form a critical conscience. Wlodkowski and Ginsberg (1995) define education as a culturally sensitive adaptation to the dynamic combination of multiple variables related to family, ethnicity, class, gender, region, and religion. All these variables contribute to the cultural identity of each student and his or her group membership. Along the same lines, Huber (1991) points out the value of teaching approaches that identify the influences of culture, language, ethnicity, gender, religion, exceptionality, socioeconomics, and family environment; this awareness can reduce the cultural discontinuity between the student's ethnic culture and the school culture.

Cummins (1986) argues that the relations of power and status between minority and majority in the world outside the classroom have an important influence on school performance. An important element of his thesis is that, because of their interactions with the dominant group, minority students feel insecure and ambivalent about the value of their 
own cultural identity, and this affects their school performance. Teachers will be better able to change this relationship if they examine their own beliefs and personal values and reconfigure the ways they interact with students from ethnic communities. According to Delpit (1995), a monocultural faculty is likely to take most decisions based on the experiences of White people and their belief systems. This happens not because White teachers are uninterested in minority students, but because as individuals we all base our interpretations of the world on our own life experiences.

Data collected by the "EScol" (Education Scholarisation) team, founded in 1987 in France by Bernard Charlot, clearly show how important cultural factors are in beginning to develop students' relationship to knowledge (Bautier, Charlot, and Rochex 2000). Their work on students' relationship to knowledge and sense of the school experience has shown that everyone has a relationship with knowledge (or the act of learning) and that the relationship has two dimensions, which they call identity and epistemic. The individual's identity consists of a set of benchmarks, goals, and practices the person engages with over time; they are reflected in the person's relationship to knowledge. It is also appropriate to speak of a group dimension of this relationship, as individuals' relationships to knowledge emerge from the relationship to knowledge of the groups they belong to. Thus the identity dimension is the way knowledge takes on meaning as people refer to models, expectations, beliefs, values, and references in anticipation of their future lives. The epistemic dimension is defined by each person's references to what they experience as the act of learning and knowing.

As Delpit (1995) stated, when we teach across boundaries of race, class, and genderwhich is the reality when we teach-we must identify and overcome the power differentials, stereotypes, and other barriers that prevent us from seeing each other as both teacher and learner. These efforts should guide teacher training, school curriculum development, instructional strategies, and every aspect of the educational process. Until we can see the world as others see it, at least partially, all the educational reforms in the world will fail. Thus, addressing cultural differences (i.e., cultural diversity) is essential to any teaching approach. It seems obvious that culturally appropriate education allows teacher and student to construct a pedagogical relationship that involves not submission to the other, but willingness to submit to an exchange with the other (Meirieu 1993). Gewirtz and Cribb (2011) suggested a critical version of multiculturalism:

More sophisticated approaches start from an anti-essentialist position. They aim to resist making assumptions about people's identities, and rather seek to engage actively and continuously with the identity projects of learners by talking with and listening to them. Underlying this position are the beliefs that (a) if we are interested in affirming people's actual identities-i.e. who they think they are-rather than in relating to them through our own categorizations and generalizations, then we have to treat them as individuals, not categories, and this involves being ready to listen to and learn from them; and (b) the discerning of people's actual identities is not something that can be done on a one-off basis because, as we have discussed, identities are not fixed but are fluid and hybrid, and evolve and are negotiated over time. (p. 144)

Culturally appropriate education is a term that has emerged from the analysis of many ethnographic studies of teachers working in intercultural settings in urban and ethnically diverse communities around the world. The term refers to the inclusion of education appropriate for students whose daily lives require working with agricultural crops as a way to enhance students' ethno-cultural identity and boost their academic achievement 
(Osborne 2001). Gay (2002) says that learning culturally appropriate uses of the characteristics, experiences, and perspectives of students from various ethnic groups is a priority in any framework for teaching. When school contents are framed from the students' perspectives, their learning experiences become more meaningful and interesting and therefore lessons are easier to absorb. Culturally appropriate education includes several specific efforts: educators must develop a knowledge base on cultural diversity, integrate cultural and linguistic diversity into the curriculum, express a permanent concern for the lives of all students and for building learning communities, and communicate with students in ways that reflect cultural diversity.

One specific component in preparing for and practicing culturally appropriate education is to consider what Gay (2002) calls the modalities of participation in discourse. The dominant communication style in schools can be characterized as receptive and passive; in contrast many social and ethnic groups use a more participative style of communication. In the first style, the speaker is active and communication is didactic (methodical). The receiver is passive. Thus, students are expected to listen quietly and carefully while the teacher speaks. They cannot speak during the key moments when their thoughts arise, but rather must wait to respond at a time orchestrated by the teacher. Generally, the teachers seek their participation by asking questions of particular students. These questions require factual answers, correct answers. In contrast, the communication styles of many ethnic groups are more active, participatory, multi-modal, and dialectical. Speakers expect that listeners will engage with them as they talk, providing timely feedback and comments. The roles of speaker and addressee are fluid and interchangeable. African Americans, for example, refer to this style of communication as call and response.

Of course these differing styles have consequences in the classroom. They can be problematic for both teachers and students. Teachers using the first style view students using the second style as discourteous, disruptive, and inappropriate. They often take action to silence them. When teachers ban the use of students' speech, they may also reduce students' responses, thus dashing their intellectual engagement and their educational efforts. As teachers or teacher educators, we can probably all recall examples of these different communication styles. We can also measure how difficult it is to let go of the style that our primary and secondary socialization led us to focus on, or our preferred style.

The Viewpoint in this issue by Steven Van Hook reports on a study designed to understand whether particular themes and images that transcend cultural dimensions may be used in teaching a student body whose students come from many cultures. The research participants were students enrolled in an international, university-level business course. Van Hook aims to find a way to "make cultural differences a secondary concern" in the classroom. Although this goal stands in contrast to the objectives of this special issue as a whole, his findings and discussion contribute to multicultural educational policies and practices. One conclusion the author draws is that teachers might avoid using content related to humour, nationalism, sex, and religion in multicultural classrooms and instead use themes that reflect the dynamics of interpersonal relationships, and images related to sports and babies.

The idea of making cultural differences a secondary concern is controversial. This goal is based in a belief that differences are a risk or problem in learning and can keep students from gaining knowledge about multiple cultures. It raises many questions. For example, should we avoid explicitly addressing religious differences in the classroom, or is it an important part of education to approach all religions with a critical lens? On the other hand, an initially transcultural approach may provide a safe base for culturally relevant teaching. 
That is, by beginning with material that seems to transcend many cultures, teachers may provide a secure base for initiating intercultural interactions that can later facilitate more in-depth cultural explorations and understandings that are fundamental to intellectual and identity development. Although it was not part of the study reported here, Van Hook raises an important question about the dominant role that the English language plays in international business education. Both of these issues, transculturalism and language of instruction, have implications for educational practices and policies.

The case study by Greg Burnett and Govinda Lingam analyzes trends in graduate education in the Pacific region with a goal of understanding students' worldviews as reflected in their theses. Because students come from and return to varied and different cultural settings, they are key stakeholders in either maintaining the status quo or contributing to social transformation. The authors systematically analyzed graduate studies conducted between 1968 and 2009, placing them into Lather's (2006) typology of research paradigms: (i) positivist, (ii) positivist/interpretivist, (iii) interpretivist, (iv) interpretivist/ emancipationist, (v) emancipationist, (vi) emancipationist/deconstructivist, and (vii) deconstructivist. They also examined the populations and issues that were the target of these projects. They found an imbalance of focus between Fijian (75\%) and Indo-Fijian research. Looking at the research paradigm, they found that most of this work is interpretivist, followed by interpretivist/emancipationist. They conclude that a lack of deconstructivist worldviews in this research limits the possibilities for transformation and that issues of access and equity have not been addressed to date. This case raises an important question: How well is university education in the Pacific placed to support students in learning and applying a deconstructivist worldview that can contribute to social transformation? Interestingly, this article touches on New Zealand's use of languages in the classroom and the ways that teachers' cultural positions impact students' development of critical thinking skills. It also provides historical context for policies and practices in the Pacific Rim. This case raises complex issues; thus, it is often consistent with points made by other authors in this volume, while sometimes calling their points into question.

In this special issue each article addresses historical artifacts, and national and educational policies that impact the opening of educational systems to cultural diversity. They illustrate the need to ground educational reform not only within a framework of history, laws, and policies but also in teachers' actions in the classroom and relationships with students. These authors' works show that language policies cannot stand independent of cultural policies such as the multiculturalism in Canada described by Gérin-Lajoie. Malakolunthu and Rengasamy's work in Malaysia that explains the evolution of educational policies impacting cultural inclusivity from the period of independence from British rule in 1959 through the New Economic Policy in 1970 to a new educational philosophy proclaimed by the Ministry of Education in 1989 and onward through the National Vision 2020. Efforts to address national languages and official languages of instruction have resulted in multicultural educational policies. The cases in Brazil, of public schools described by Akkari and an international school described by Bagnall, identify many of the challenges in opening educational systems within a conservative context and offer specific strategies for addressing obstacles. Suggestions for educating indigenous teachers, and implementing positive and ethnic quotas in some institutions, highlight international approaches that have been adapted to local contexts. In the case of Canada (Gérin-Lajoie) we learn from the challenges of linking local provincial school policies to federal policies concerning the two national languages and the rights of Aboriginal peoples.

In summary, all approaches that seriously consider the role of culture in educational processes are based on two assumptions. First, they see the languages, cultures, and diverse 
perspectives of students as essential resources and not as risks or problems. Second, they emphasize that all forms of schooling are culturally and politically constructed as a historical product of particular groups with particular interests and values specific to a particular moment in the history of a society.

\section{References}

Akkari, A., \& Loomis, C. (1998). Toward a new understanding of language minority students' experiences of bilingual education in the United States. Bulletin Suisse de Linguistique Appliquée, 67, 31-59.

Akkari, A., Loomis, C., \& Bauer, S. (2012). From accommodating to using diversity by teachers in Switzerland. The Journal of Multiculturalism in Education, 7(1), 1-11.

Akkari, A., \& Payet, J.-P. (2010). Transformations des systèmes éducatifs dans les pays du Sud. Entre globalisation et diversification [Transformations of education systems in developing countries between globalization and diversification]. Bruxelles: De Boeck.

Au, K., \& Kawakami, A. (1994). Cultural congruence in instruction. In E. Hollins, J. King, \& W. Hayman (Eds.), Teaching diverse populations: Formulating a knowledge base (pp. 5-23). Albany: State University of New York Press.

Banks, J., \& Lynch, J. (Eds.). (1986). Multicultural education in Western societies. London: Holt, Rinehart \& Winston.

Bautier, E., Charlot, B., \& Rochex, J.-Y. (2000). Entre apprentissages et métier d'élève: Le rapport au savoir [Between learning and their role as students: The relationship to knowledge]. In A. Van Zanten (Ed.), L'école, l'état des savoirs (pp. 179-188). Paris: La Découverte.

Berque, J. (1985). L'immigration à l'école de la République: rapport au ministre de l'éducation nationale [Immigration within the school of the Republic: Report to the Minister of National Education]. Paris: La Documentation Française.

Bourdieu, P., \& Passeron, J.-C. (1977 [1970]). Reproduction in education, society and culture. Translated by Richard Nice. London: Sage Publications.

Cummins, J. (1979). Cognitive/academic language proficiency, linguistic interdependence, the optimal age question and some other matters. Toronto: Ontario Institute for Studies in Education.

Cummins, J. (1986). Empowering minority students: A framework for intervention. Harvard Educational Review, 56(1), 18-36.

Dasen, P., \& Akkari, A. (Eds.) (2008). Educational ideas from the majority world. Delhi: Sage India.

Delpit, L. (1995). Other people's children. New York: The New Press.

Gay, G. (2002). Preparing for culturally responsive teaching. Journal of Teacher Education, 53(2), 106-116.

Gewirtz, S., \& Cribb, A. (2011). Understanding education: A sociological perspective. Cambridge, UK: Polity Press.

Huber, T. (1991, October). Restructuring to reclaim youth at risk: Culturally responsible pedagogy. Paper presented at the 13th annual meeting of the Mid-Western Educational Research Association, Chicago. (ERIC Document No. ED 341655).

Jacob, E., \& Jordan, C. (1987). Moving to dialogue. Anthropology and Education Quarterly, 18(1), 259-261.

Klein, G. (1994). The need to maintain mother tongues. Die Suid-Afrikaan (special issue on education).

Ladson-Billings, G. (1990). Culturally relevant teaching: Effective instruction for black students. The College Board Review, 7(15), 20-25.

Meirieu, P. (1993). L'envers du tableau [Behind the blackboard]. Paris: ESF éditeur.

Novick, R. (1996). Developmentally appropriate and culturally responsive education: Theory in practice. Portland, OR: Northwest Regional Educational Laboratory. (ERIC Document No. ED 397 985).

Osborne, B. (Ed.). (2001). Teaching, diversity and democracy. Melbourne: Common Ground.

Phuntsog, N. (1999). The magic of culturally responsive pedagogy: In search of the genie's lamp in multicultural education. Teacher Education Quarterly, 26(3), 97-111.

Serpell, R., \& Ganapathy, H. (2002). Challenging Western hegemony through systematic study of cultural diversity: An undergraduate course on child development. Baltimore: University of Maryland, Baltimore County.

Wlodkowski, R. J., \& Ginsberg, M. B. (1995). A framework for culturally responsive teaching. Educational Leadership, 53(1), 17-21. 


\section{Author Biographies}

Abdeljalil Akkari (Tunisia and Switzerland) is professor and director of a research group on international education at the University of Geneva. He is also a regular consultant for UNESCO and other international organizations, and was the dean for research at the Higher Pedagogical Institute HEP-BEJUNE in Bienne, Switzerland. His major publications include studies on educational planning, multicultural education, teacher training, and educational inequalities. His current research interests focus on teacher education and reforms of educational systems in a comparative and international perspective.

Colleen Loomis (United States and Canada) is a senior social scientist at the University of Geneva in the Faculty of Psychology and Education Sciences and an associate professor at Wilfrid Laurier University in Waterloo, Ontario. Her research focuses on how schools and communities work together to ensure equality in quality education, particularly for persons living in poverty, members of multicultural groups, and immigrants. Her work is situated at the intersection of the disciplines of psychology and education and is based in both ecological and multicultural frameworks. 